\title{
Snow cover variability and snowmelt in a high-altitude ungauged catchment
}

\author{
Rui Wang, ${ }^{1,2}$ Zhijun Yao, ${ }^{1 *}$ Zhaofei Liu, ${ }^{1}$ Shanshan Wu, ${ }^{1}$ Liguang Jiang ${ }^{1}$ and Lei Wang ${ }^{1,2}$ \\ ${ }^{1}$ Institute of Geographical Sciences and Natural Resources Research, Chinese Academy of Sciences, 11A Datun Road, Beijing, 100101, China \\ ${ }^{2}$ University of Chinese Academy of Sciences, 19A Yuquan Road, Beijing, 100049, China
}

\begin{abstract}
:
Snow variability is an integrated indicator of climate change, and it has important impacts on runoff regimes and water availability in high-altitude catchments. Remote sensing techniques can make it possible to quantitatively detect the snow cover changes and associated hydrological effects in those poorly gauged regions. In this study, the spatial-temporal variations of snow cover and snow melting time in the Tuotuo River basin, which is the headwater of the Yangtze River, were evaluated based on satellite information from the Moderate Resolution Imaging Spectroradiometer snow cover product, and the snow melting equivalent and its contribution to the total runoff and baseflow were estimated by using degree-day model. The results showed that the snow cover percentage and the tendency of snow cover variability increased with rising altitude. From 2000 to 2012 , warmer and wetter climate change resulted in an increase of the snow cover area. Since the 1960s, the start time for snow melt has become earlier by 0.9-3 days/10a and the end time of snow melt has become later by 0.6-2.3 days/10a. Under the control of snow cover and snow melting time, the equivalent of snow melting runoff in the Tuotuo River basin has been fluctuating. The average contributions of snowmelt to baseflow and total runoff were $19.6 \%$ and $6.8 \%$, respectively. Findings from this study will serve as a reference for future research in areas where observational data are deficient and for planning of future water management strategies for the source region of the Yangtze River. Copyright (c) 2015 John Wiley \& Sons, Ltd.
\end{abstract}

KEY WORDS snow cover; snowmelt; snow melting time; climate change; headwater of the Yangtze River

Received 2 July 2014; Accepted 25 February 2015

\section{INTRODUCTION}

Snow cover is particularly vulnerable to climate change (Barnett et al., 2005; Bavay et al., 2013), and its variability heavily influences regional runoff dynamics (Horton et al., 2006; Bavay et al., 2009). In low and middle latitudes, the snow distribution, snow melting time (SMT) and snow melting equivalent in high-altitude regions interact with local climatic and hydrological factors, and the associated changes can have large effects not only on the runoff regime but also on water resources and ecological communities in downstream areas (Stewart et al., 2004; Siderius et al., 2013). However, mountain climate and weather are extremely variable in time and space, and subject to the impacts of latitude, altitude and topography (Barry, 1981). Therefore, quantitative analyses on regional snow cover, snowmelt and its hydrologic effects are often limited by the lack of adequate snow observational data in mountain areas.

*Correspondence to: Zhijun Yao, Institute of Geographical Sciences and Natural Resources Research, Chinese Academy of Sciences, 11A Datun Road, Beijing, 100101, China.

E-mail: yaozj@igsnrr.ac.cn
Detection of snow covered area from space has been possible since the early 1960s (Tekeli et al., 2005). With advances in remote sensing technology, snow cover information derived from satellites has become an increasingly valuable data source ( $\mathrm{Pu}$ and $\mathrm{Xu}, 2009)$. Since the inception of the Moderate Resolution Imaging Spectroradiometer (MODIS) in 1999, MODIS data have been widely used to analyze spatial and temporal variations of snow cover; MODIS data are particularly useful because of characteristics such as multi-band datasets with moderate spatial and high temporal resolutions (Painter et al., 2009; Parajka et al., 2010; Yang et al., 2012). Based on the normalized-difference snow index, Hall et al. (2002) developed a snow cover product with a $500 \mathrm{~m}$ spatial resolution using MODIS observations, and this has improved the classification accuracy of snow and furthered the understanding of snow dynamics and its influences in remote mountainous regions. Jain et al. (2010) applied the MODIS snow cover product to extract snow coverage in a Himalayan basin during the initial stage of melt. Biggs and Whitaker (2012) studied a mountainous area located in California, USA, and found that MODIS snow cover products were crucial for obtaining estimates of snow melting 
equivalents. Parajka and Blöschl (2008) performed simulations of snow water equivalents for 148 catchments in Austria and showed that the use of the MODIS snow cover data improved the snow model performance and slightly improved the runoff model performance.

In high-altitude areas of Asia where glaciers and snow are concentrated, changes of snow and ice in response to climate change and the associated effects on hydrological regimes are of great concern. Current studies have mostly focused on the Himalayan region, which is the source for many large rivers such as the Ganges River and the Yarlung Zangbo River (Singh and Kumar, 1997; Sharma et al., 2012; Mishra et al., 2014). However, studies in other regions are also valuable. The Tuotuo River, which is located in the hinterland of the QinghaiTibet Plateau, is the headwater of the Yangtze River that supports one third of the Chinese population. Glaciers account for $1.92 \%$ of the total area of the Tuotuo River basin, and it has been reported that the recharge rate of glacier melting to runoff is $18.4-33.7 \%$ in this region and that the rates are exhibiting an increasing trend with climate warming (Yang et al., 2000; Wu et al., 2013). Actually, year-round snow is present not only in the glaciation area but also in the lower areas of the Tuotuo River basin, where snowfall ratios above $18.5 \%$ of the total precipitation are observed because of the cold weather. Therefore, snow melting is also an important source of river runoff in the basin. A quantitative analysis of the contribution of snowmelt to runoff in the Tuotuo River basin would be useful for understanding the runoff composition of the Yangtze River's headwaters, which is information that is needed for the appropriate allocation and management of water resources downstream. Because the contribution from snowmelt is controlled by both the length of the snow melting period (SMP) and the amount of snow melting equivalent, the objectives of this study were as follows: (1) to obtain the spatial-temporal distribution of snow cover area (SCA) in the Tuotuo River basin; (2) to evaluate the dynamics of SMT; and (3) to calculate the equivalent of snow melting runoff (SME) and its contribution to the total runoff and baseflow quantitatively.

\section{MATERIAL AND METHODS}

\section{Study area}

The Tuotuo River, which has a length of $346 \mathrm{~km}$, originates from the Ginger Goodey Glacier in the southwestern Geladandong glaciated area of $\mathrm{Mt}$ Tanggula. The river basin lies between the latitudes of $33^{\circ} 22^{\prime} 47^{\prime \prime}$ to $34^{\circ} 55^{\prime} 00^{\prime \prime} \mathrm{N}$ and the longitudes of $90^{\circ} 31^{\prime} 55^{\prime \prime}$ to $92^{\circ} 55^{\prime} 36^{\prime \prime} \mathrm{E}$, and it has an area of $17600 \mathrm{~km}^{2}$ (Figure 1). The study area is higher in the west than in the east, and it is located at relatively extreme elevations ranging from 4469 to $6523 \mathrm{~m}$ above sea level (m.a.s.l.). The vegetation coverage in the basin is about 55-65\%, and high-cold meadows and steppe are the main types of pasturelands. Vegetation types in the basin include wormwood, kobresia and various alpine shrub meadow plants (Wang and Cheng, 2000). The basin contains several types of poor soils including alpine desert soil, alpine meadow soil and alpine grassland soil (Wang et al., 2001). According to the Glacier Inventory of China, the glaciers in the Tuotuo River basin have a total area and volume of 389.09 and $42.15 \mathrm{~km}^{3}$, respectively (Shi et al., 2005).

The Tuotuo River basin is characterized by an alpine semi-arid and semi-humid climate transition zone (Chen et al., 2008), and it experiences only two seasons each year that consist of a dry season from November to April and a wet season from May to October (Figure 2). The observed data from the Tuotuo River meteorological station shows that the annual average precipitation is $290.9 \mathrm{~mm}$, and it has increased significantly since 2000 . The annual precipitation is unevenly distributed, and almost $96 \%$ of the precipitation falls during the wet season. The annual average temperature is $-3.9^{\circ} \mathrm{C}$, and there has been a rising trend in the temperature from the 1990s until the present with a cumulative increase of about $1.75^{\circ} \mathrm{C}$. Temperatures are typically above $0{ }^{\circ} \mathrm{C}$ between May to September and below $0^{\circ} \mathrm{C}$ during the other months, which is beneficial to the high snowfall ratio. Synchronization of high temperatures and ample precipitation leads to the superposition of the melting runoff and rainfall runoff during the wet season, which creates a more complex runoff regime in the study area.

\section{Data sources}

The MOD10A2 snow cover product derived from the MODIS TERRA satellite is an 8-day combination dataset that is available at a resolution of $500 \mathrm{~m}$. It is capable of reducing cloud obscuration with a classification accuracy of 84.5-95.9\% (Zhou et al., 2005). There are 302 images covering the Tuotuo River basin during 2000-2012, which meet the needs of this study. These data were converted to both monthly data for the analysis of the SCA and daily data via origin interpolation for the calculation of the SME.

Supporting data used in this study include data on the elevation, weather and runoff characteristics. The digital elevation model, which is retrieved from the International Scientific Data Service Platform with a $90 \mathrm{~m}$ resolution, was used to divide the basin into elevation zones. The daily discharge data from 1960 to 2012 are obtained for the Tuotuo River hydrometric station from the Hydrology 


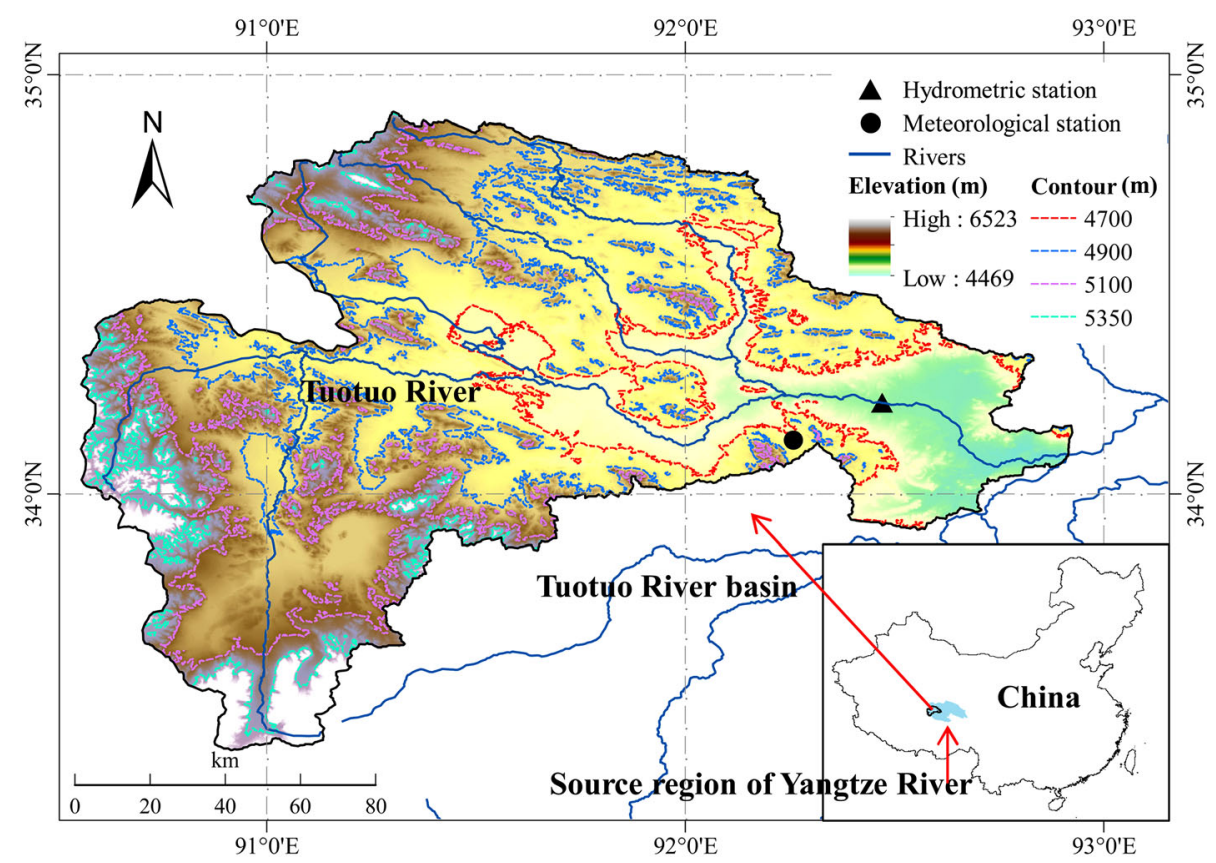

Figure 1. Topography of Tuotuo River basin in western China showing location of observed stations
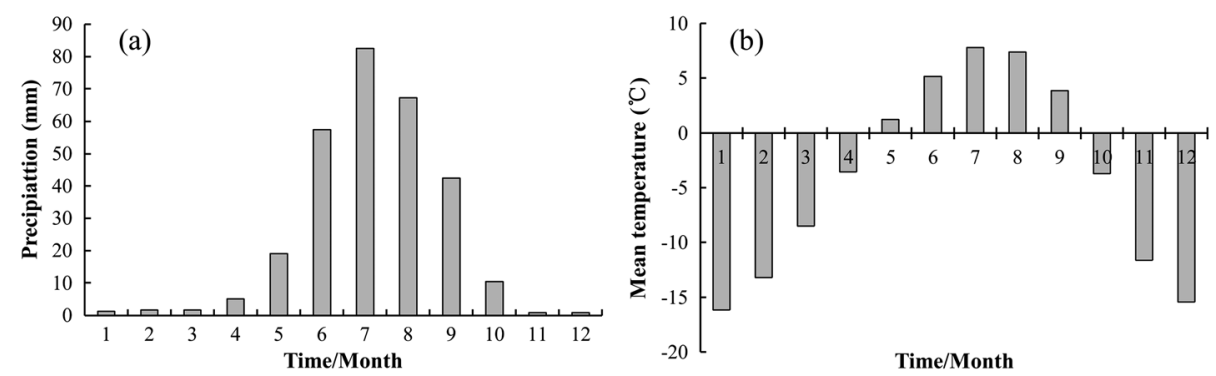

Figure 2. Monthly distribution of averaged (a) precipitation and (b) air temperature from the Tuotuo River meteorological station for baseline period (1960-2012)

Bureau of Qinghai. Data from May to October are observational, and the remaining data are estimated based on the temporary curve method. Because the investigation found that the Tuotuo River is almost frozen during the dry season, in consideration of the error of the method, this study only took considerations of the wet season into account. Meteorological data, which include daily precipitation and average air temperatures, are provided by the China Meteorological Data Sharing Service System. The data series are from 1960 to 2012, and the locations of the stations are shown in Figure 1. In addition, because temperature plays a key role in the processes of snow accumulation and melt, it is important to evaluate the spatial variation of the temperature. Chen et al. (2014) obtained monthly temperature raster data for the Qinghai-Tibet Plateau with resolution of $8 \mathrm{~km}$ by using the ANUSPLIN interpolation software. After tailoring and resampling processing, these data were applied in this study.

\section{Main methods}

Analysis of snow variables. Elevation is a key factor controlling climate, snow cover and snowmelt (Woo and Thorne, 2006). To determine the spatial distribution of individual snow variables such as SCA, SMT and SME, as well as the correlation between these variables and elevation, the Tuotuo River basin was divided into five elevation zones (Table I). The base line of zone 5 (5350 m.a.s.l.) was according to the glacier area from $\mathrm{Wu}$ et al. (2013); therefore, this top zone was identified as a permanent snow covered area, and other zones were classified as seasonal snow covered areas.

Calculation of the SMT. Snow melting time was considered from three aspects including the snowmelt start time (ST), the snowmelt end time (ET) and the snowmelt runoff time. Temperature in winter and spring is the primary controller during the start period of melt (Wipf et al., 2009). 
Table I. Elevation zone distribution of the tuotuo river basin

\begin{tabular}{lcccc}
\hline $\begin{array}{l}\text { Elevation } \\
\text { zone }\end{array}$ & $\begin{array}{c}\text { Elevation } \\
\text { range }\end{array}$ & $\begin{array}{c}\text { Average } \\
\text { elevation }(\mathrm{m})\end{array}$ & $\begin{array}{c}\text { Zone area } \\
\left(\mathrm{km}^{2}\right)\end{array}$ & $\begin{array}{c}\text { Proportion } \\
\text { of basin }(\%)\end{array}$ \\
\hline 1 & $4469-4700$ & 4611 & 3408 & 19.1 \\
2 & $4700-4900$ & 4805 & 5826 & 32.7 \\
3 & $4900-5100$ & 4989 & 5208 & 29.2 \\
4 & $5100-5350$ & 5201 & 2393 & 13.4 \\
5 & $5350-6523$ & 5566 & 987 & 5.5 \\
\hline
\end{tabular}

To prevent error from snow loss due to wind blow, which could mistakenly be associated with the melting, a simple algorithm based on cumulative air temperature was developed to obtain the ST of snowmelt, and then, it was analogized for the ET. Because $0{ }^{\circ} \mathrm{C}$ is usually regarded as the threshold for snow melting (Kane et al., 1997; Kirdyanov et al., 2003; Bookhagen and Burbank, 2010), it can be deduced that the snowmelt process starts when the average air temperature above $0^{\circ} \mathrm{C}$ continues for a few days. Therefore, on the cumulative temperature curve, there are opposite trends before and after the ST of snowmelt, performing reducing and increasing, respectively, shown in Figure 3a. Accordingly, the first and second inflection points were identified as the ST and ET of the snowmelt, respectively. Moreover, the correlation between cumulative air temperature and snowmelt was confirmed in $\mathrm{Wu}$ et al. (2012) and $\mathrm{Yu}$ et al. (2013).

The snowmelt runoff time, as indicated by the timing of the centre of mass of flow, or 'centre time' (CT) measure (Stewart et al., 2004), was calculated with Equation (1). The CT measure was easily and reliably determined, and it was comparatively insensitive to spurious inter-annual variations in flow. In addition, because the CT measure has been used in previous studies, comparison of the results can be facilitated (Regonda et al., 2005; Westerling et al., 2006).

$$
\mathrm{CT}=\sum q_{i} t_{i} / \sum q_{i}
$$

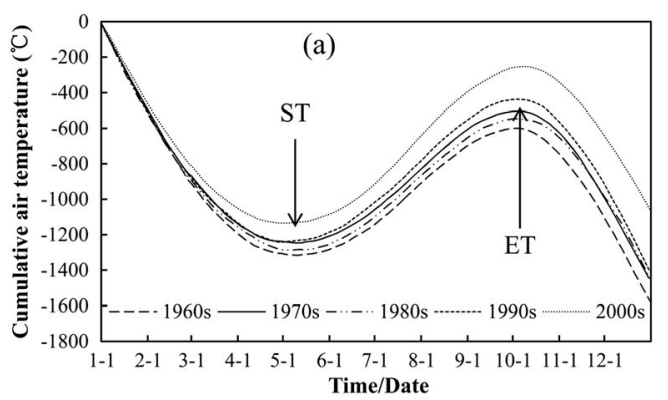

Figure 3. Variations of (a) daily cumulative air temperature and (b) degree-day factor, taking the observed data from the Tuotuo River Moteorological Station as an example

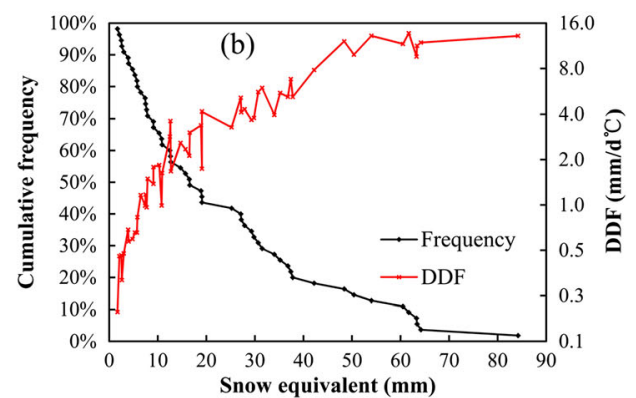

where $t_{i}$ is time in days from the beginning of the water year (October 1) and $q_{i}\left(\mathrm{~m}^{3}\right)$ is the corresponding streamflow for water year day ${ }_{i}$. Therefore, CT is a date given in days.

Estimation of the SME. The SME was estimated by the typical degree-day model using the calculation shown in Equations (2) and (3). The degree-day model was based on an assumed relationship between ablation and air temperature, which was usually expressed in the form of a positive cumulative temperature (Hock, 2003). Although this involves a simplification of the complex processes that can be more properly evaluated by the energy balance of the snow surface, degree-day model can often match the performance of energy balance models on a catchment scale (WMO, 1986; Ohmura, 2001); therefore, it is widely used in snowmelt studies (Immerzeel et al., 2010; Mukhopadhyay and Dutta, 2010).

$$
\sum_{i=1}^{\mathrm{n}} M_{i}=D D F \sum_{i=1}^{n} T_{i}^{+}
$$

where $M_{i}(\mathrm{~mm})$ is the water equivalent of snow melt during the period of $n$ (day), $D D F\left(\mathrm{~mm} / \mathrm{day}{ }^{\circ} \mathrm{C}\right)$ is the factor of proportionality being the degree-day factor (DDF), and $T^{+}\left({ }^{\circ} \mathrm{C}\right)$ is the sum of positive air temperatures of each time interval.

$$
\sum_{i=1}^{n} Q_{m i}=\sum_{i=1}^{\mathrm{n}} M_{i} S_{i}(i=1,2, \ldots, 5)
$$

where $Q_{m i}\left(\mathrm{~m}^{3}\right)$ is the SME in elevation zone $i\left(\mathrm{SME}_{i}\right)$, and $M_{i}(\mathrm{~mm})$ and $S_{i}\left(\mathrm{~km}^{2}\right)$ are the water equivalent of snow melt and snow cover area $\left(\mathrm{SCA}_{i}\right)$ of the zone $i$, respectively.

The DDF, which reflects regional differences of the response of snowmelt to climate directly, is most important to ensure the accuracy of results (Zhang Y et al., 2006). Singh et al. (2000) has listed several DDFs for snow and ice that were reported by various 
investigators all over the world and showed high variability of this factor. In this study, the parameter DDF was set to different values for different elevation zones and different periods to enhancing the reliable and valuable of the results. The DDF value for the lowest zone was calculated by using the observed data of daily air average temperature and daily snowfall water equivalent from the Tuotuo River meteorological station during 1960-2012. The MODIS snow product showed that the snow covered area in the lowest zone reduced significantly from May, and not only the remote sensing but also our field surveys found that there was almost no snow cover in this area from the end of June to the end of September. In addition, the evaluation of ST and ET based on the air temperature data revealed that the major SMP and accumulation period is from May to September and from last October to April, respectively, in this elevation zone. Therefore, the snowmelt equivalents during May and June can be considered to equalling the total water equivalent of snowfall from last October to June. As a result, the range of DDF value is 0.2 to $13.71 \mathrm{~mm} /$ day $^{\circ} \mathrm{C}$, with the average value of $4.14 \mathrm{~mm} /$ day ${ }^{\circ} \mathrm{C}$ for this elevation (Figure $3 \mathrm{~b}$ ). This magnitude is consistent with the value for similar elevations from Zhang Y et al. (2006).

However, because of the lack of observed data, the DDF value cannot be calculated directly for zones 2-5. Therefore, the DDF values of snow and snow-ice ablation for the highest zone (above 5350 m.a.s.l.) were set to 8.5 and $9.6 \mathrm{~mm} /$ day ${ }^{\circ} \mathrm{C}$, respectively, according to the study from Qiao et al. (2010), which was carried out for the small Dongkemadi Glacier (5460-5710 m) located on the Tanggula Range also. The snow-ice melting DDF value of $9.6 \mathrm{~mm} /$ day $^{\circ} \mathrm{C}$ was used from July to September because the ice ablation will begin with the increasing of air temperature and solar radiation. Using the highest and lowest bounds, the snow DDF value for zones 2 to 4 can be obtained by applying the linear fitting method (Table II).

Baseflow separation. In consideration of the synchronization of melting runoff and rainfall runoff during the wet season, in this study, a baseflow separation was performed whereby the correlation between melting runoff, baseflow and total discharge was analysed to

Table II. Degree-day factors for different elevation zones in the tuotuo river basin

\begin{tabular}{lccccc}
\hline $\begin{array}{l}\text { Elevation } \\
\text { Zone }\end{array}$ & 1 & 2 & 3 & 4 & 5 \\
\hline $\left.\begin{array}{l}\mathrm{DDF} \\
(\mathrm{mm} / \text { day }\end{array}{ }^{\circ} \mathrm{C}\right)$ & 4.14 & 5.23 & 6.32 & 7.41 & $\begin{array}{l}8.50 \text { for snow } \\
9.60 \text { for snow-ice }\end{array}$
\end{tabular}

reveal the contribution of snowmelt in the Tuotuo River basin. Several filter algorithms for baseflow separation were developed, and these have been used under different runoff patterns in various areas (Eckhardt, 2008; Partington et al., 2012; Li et al., 2014). The comparison indicated that the two-parameter filter proposed by Eckhardt (2005) was most reasonable, and the baseflow was calculated with Equation (4).

$$
q_{i}=\frac{\alpha \times\left(1-\beta_{\max }\right) \times q_{i-1}+(1-\alpha) \times \beta_{\max } \times Q_{i}}{1-\alpha \times \beta_{\max }}
$$

where $q_{i}\left(\mathrm{~m}^{3}\right)$ is the baseflow and $Q_{i}\left(\mathrm{~m}^{3}\right)$ is the discharge of total runoff observed from hydrological station. $\alpha$ is the recession constant, the value of which is 0.925 (Nathan and Mcmahon, 1990). $\beta_{\max }$ is the maximum value of the baseflow index, which can be modelled by the algorithm, that is the $\beta$, which would be obtained if a constant time series were filtered. Eckhardt (2005) suggested to set $\beta_{\max }=0.80$ for perennial streams with porous aquifers, $\beta_{\max }=0.50$ for ephemeral streams with porous aquifers and $\beta_{\max }=0.25$ for perennial streams with hard rock aquifers.

The terms Q90 and Q50 represent discharges that are exceeded $90 \%$ and $50 \%$ of the time, respectively, and they are determined by the use of a flow-duration curve. The ratio $(\mathrm{Q} 50 / \mathrm{Q} 90)$ can represent the variability of low-flow discharges, and its reverse ratio (Q90/Q50) was interpreted as an index representing the proportion of streamflow originating from groundwater stores, excluding the effects of the catchment area (Smakhtin, 2001). Therefore, the discharge of baseflow estimated by a filter can be validated by multiplying this ratio with the total runoff.

\section{RESULTS}

\section{Change of the SCA}

Annual variance. Monthly average SCA reached its lowest point in July and peaked in October in the Tuotuo River basin. At the lowest point, the SCA extended over $4.1 \%$ of the total area of the basin, and at the highest point, it extended over $29 \%$ of the total area. Although the responses of snow cover to climate during the dry season and wet season were different (Table III), SCA first declined and then increased during both of the two seasons (Figure 4a). During the wet season, negative correlations were observed between the SCA and climate factors, which indicated that the reduction of the SCA during the first half of the period analysed was due to increasing melt in association with increasing temperature and rainfall, whereas the increase of SCA in the second half of the period resulted from a decrease in temperature that advanced the snowfall ratio. In contrast, positive correlations between the SCA and climate factors were observed during the dry season, which suggested that the change of 
Table III. Pearson's R of correlation of SCA with temperature and precipitation for period of 2000-2012

\begin{tabular}{lllllll}
\hline & \multicolumn{2}{c}{ Wet season } & & \multicolumn{2}{c}{ Dry season } \\
\cline { 2 - 3 } \cline { 5 - 6 } & SCA - P & SCA - T & & SCA - P & SCA - T \\
\hline Pearson correlation & $-0.985^{* *}$ & $-0.977^{* *}$ & & $0.874^{* *}$ & $0.921^{* *}$ \\
Partial correlation & $-0.632^{*}$ & -0.266 & & $0.494 *$ & $0.718^{*}$ \\
\hline
\end{tabular}

$\mathrm{T}$ is temperature, and $\mathrm{P}$ is precipitation. Partial correlation means the pearson correlation between two variables under the control of the other two variables.

**is significant at the 0.01 level.

*is significant at the 0.05 level.

SCA was determined by the magnitude of snowfall directly, and this was in accordance with the conclusions reached for the Himalayan regions (Mishra et al., 2014). However, snow accumulation in the Tuotuo River basin typically only occurred in April, May and October because precipitation was very limited during the dry season.

The annual variance of the SCA was intense in high elevation areas and relatively weak in low elevation areas of the Tuotuo River basin. During 2000-2012, the annual mean amplitudes of the SCA in zones 1 to 5 were $12.3 \%$, $18 \%, 32 \%, 40.7 \%$ and $28.9 \%$, respectively; these data were expressed as the percentage of the individual zonal area. The permanent snow covered area (above 5350 m.a. s.l.) continued to have a large SCA, and the SCA amounted to $47-76 \%$ of the total area of zone 5 ; in contrast, the SCA below an elevation of 4700 m.a.s.l. (zone 1) was small, even though this zone occupied 19\% of the basin area (Figure $4 \mathrm{~b}$ ). In the middle areas of the basin (zones 2 to 4 ), the SCA was more significant in zone 3 than in the other two zones, which indicated that the seasonal snow cover was mostly concentrated at elevations of 4900-5100m.a.s.l. in the Tuotuo River basin. It was also worth noting that the SCA in zone 2 and zone 4 were similar; however, the area of zone 4 was only equal to $40 \%$ of zone 2 . Therefore, it can be inferred that cold weather resulted in significant snowfall and snow cover in the higher elevations, and especially during the wet season, the snow cover was mainly distributed in the areas above 4900 m.a.s.l. in the basin.

Inter-annual variation. The positive trends in the SCA at the annual and seasonal scales were found in the study area during 2000-2012, whereas trends during the wet season were not found to be significant at the $95 \%$ confidence level. Since 2008, the yearly average SCA has been close to or exceeded $20 \%$ of the basin area (Figure $5 a$ ), and this significant increase was mainly derived from changes during the dry season (Figure 5b). However, the impact of snow cover during the wet season on the annual SCA was greater in general (Figure 5c). In addition, compared to the seasonal snow covered area where the percentage of zonal SCA did not exceed $40 \%$, the increasing trend of the SCA in the permanent snow covered region is slightly greater.

The percentage of time for snow cover in the study area is shown in Figure 6, indicating that compared with those in 2000 , more regions were covered by snow for longer periods in 2012. In particular, the snow covered time during the dry season increased significantly. In 2000, the areas where snow covered time was longer than 1 and 2 months represented $13.7 \%$ and $7 \%$ of the basin area, respectively; however, these two proportions increased to $77.9 \%$ and $14.5 \%$ in 2012 , respectively.

\section{Dynamic of the SMT}

Change of the snow melting period. After converting the monthly spatial temperature to zonal average values, a linear regression was performed to obtain the correlation between the zonal temperatures and the observations from the meteorological stations for each year. Individual regression equations were obtained for each elevation zone during every year, and the $R^{2}$ values ranged from 0.990 to 0.999 . Therefore, these equations can be used to extend the spatial extent of observed daily temperatures to creating the zonal daily average temperature datasets. The ST, which was evaluated with the cumulative temperature curve, occurred most frequently
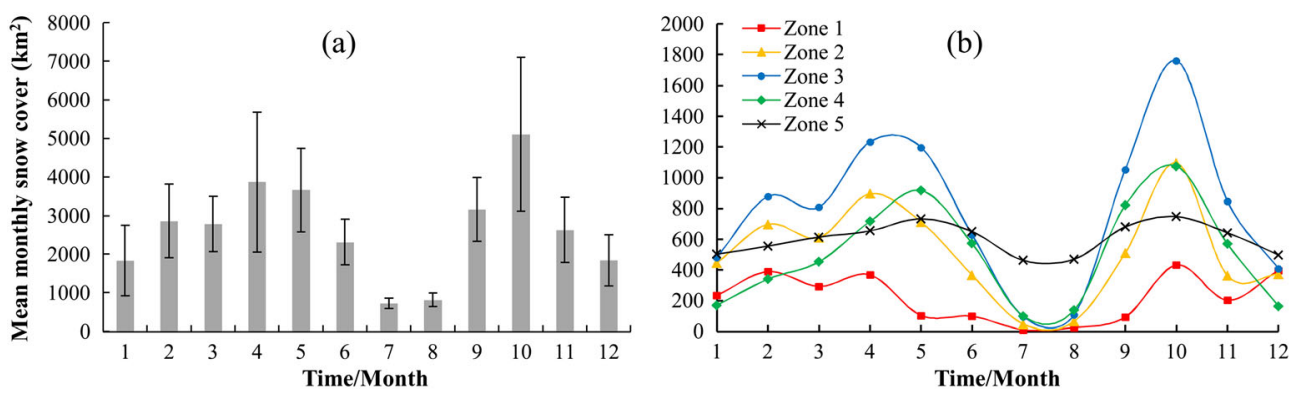

Figure 4. Mean monthly SCA (a) in Tuotuo River basin with error bar equal to standard deviation and (b) in five elevation zones for the period of 2000-2012 
(a)

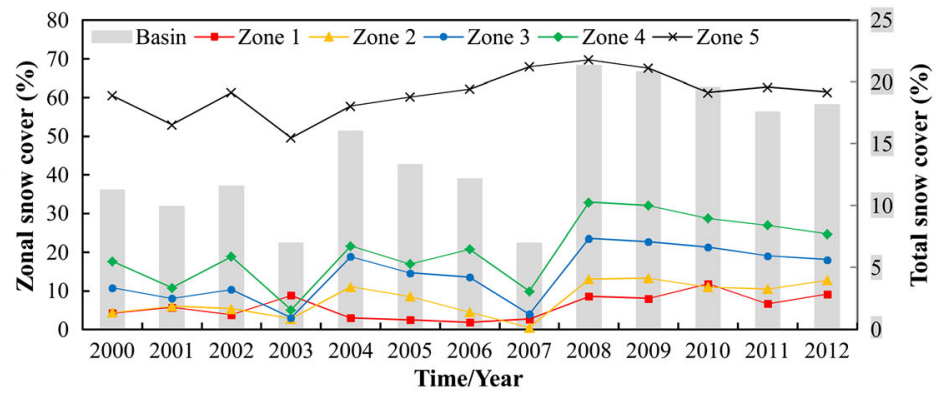

(b)

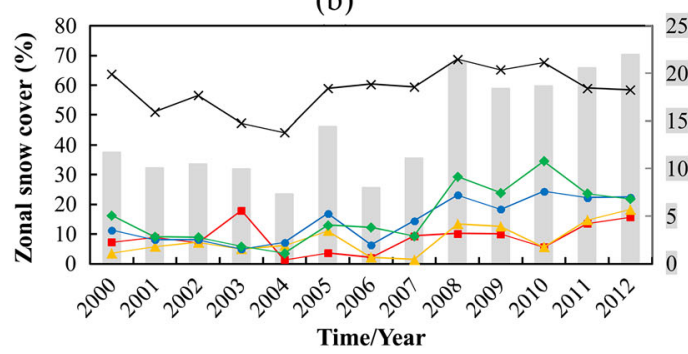

(c)

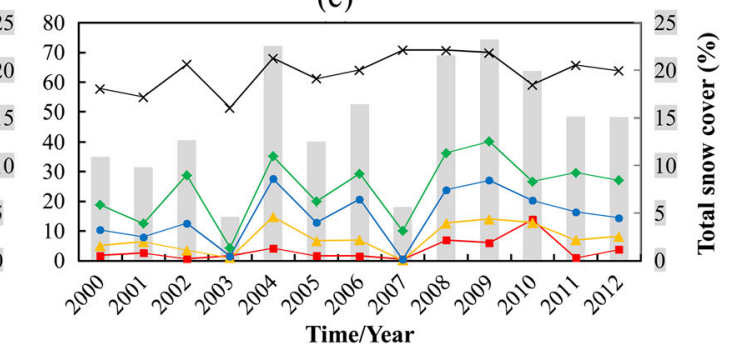

Figure 5. Average SCA shown as the percentage of the zonal area between 2000 and 2012 for (a) all the year, (b) dry season and (c) wet season, showing the SCA of each elevation zone with lines and the total SCA in the basin with bars

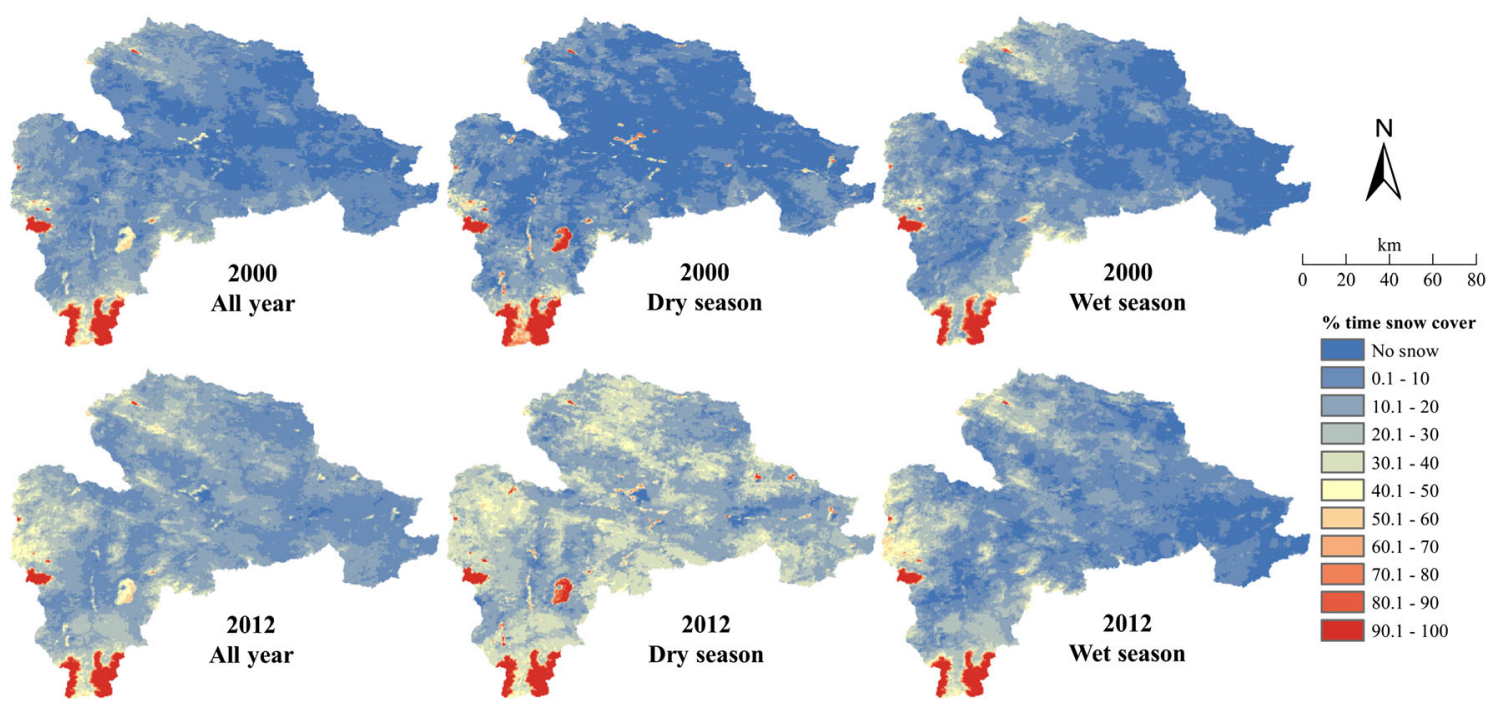

Figure 6. Annual and seasonal percentage of time of snow cover in the Tuotuo River basin for years 2000 and 2012

from the start of May to mid-June, and the ET occurred most frequently from the start of September to the end of September. Obvious changes in the ST and ET were found for different elevations whereby the ST became later and ET became earlier as elevations increased; therefore, the SMP became shorter at higher elevations.

As a result of warming in the dry season (Kang et al., 2007), the STs shifted to earlier time in the Tuotuo River basin between 1960 and 2012, and these shifts were significant at the $95 \%$ confidence level except for those in zone 4 . The most significant advances in ST were found in zone 5 and zone 1 , which were 3 and 2.6 days earlier per decade on average, respectively, whereas the advance rate in the ST was about 0.9-1.6 days/10a in the central regions of the basin (Figure 7a). Climate changes also caused the ETs to shift to later time, especially in zone 4, where the delayed rate in the ET was about 2.3 days/10a; this shift was significant at the $95 \%$ confidence level (Figure 7b). The delayed rates at elevations above 5350 m.a.s.l. and below 5100 m.a.s.l. were 0.6 and 1-1.4 days/10a, respectively. Therefore, the SMP in the basin more or less grew, which should have increased the supply of snowmelt to the runoff.

Fluctuation of the CT. The CT of the outlet in the Tuotuo River basin was mostly in mid-July. The frequencies of 

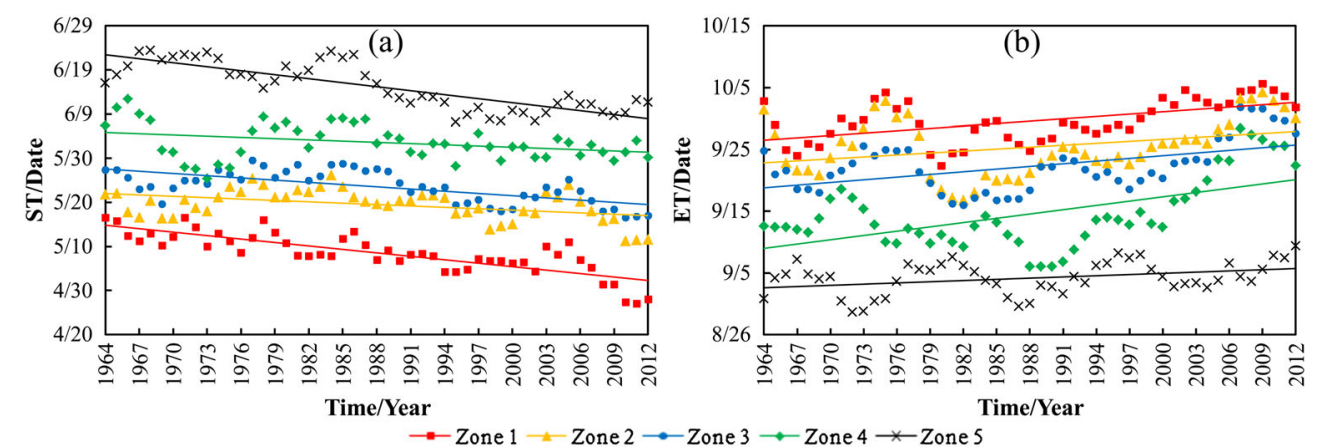

Figure 7. Five-year moving average values of (a) ST and (b) ET in five elevation zones of the Tuotuo River basin between 1960 and 2012

the CT in mid to late July and in the whole of July were $53 \%$ and $67.3 \%$, respectively, for the 53 years between 1960 and 2012. Aurela et al. (2004) and Stone et al. (2002) suggested that climate warming can play a key role in changes of the CT. In the study area, fluctuating trends in the CT were also attributed to climate change (Figure 8). During 1960-1979 and after 2000, the CT shifted towards an earlier time. Especially, the average CT during 1975-1979 was 16 days earlier than that during 1970-1974, which was likely caused by the combined effects of warmer and wetter climate conditions. During the 1980s and 1990s, the CT gradually became more delayed over time, and these changes were found to be significant at the $95 \%$ confidence level. Except for the colder climate during 1985-1989, temperatures did not change dramatically during these two decades; therefore, the reduced amount of precipitation was likely the main driving factor for the changes in the CT. In addition, the strong disturbance in the CT during 1985-1989 could be interpreted as sensitivity to climate change (Khadka et al., 2014).

Earlier CTs almost corresponded to shorter SMPs, and the positive correlation between the CT and SMP at higher elevations, which had more snow cover, was strong. This illustrated that SMTs along with both temperature and runoff observations can be used to express the response of the snow melting process to climate change, which increased with elevation. Lu et al.

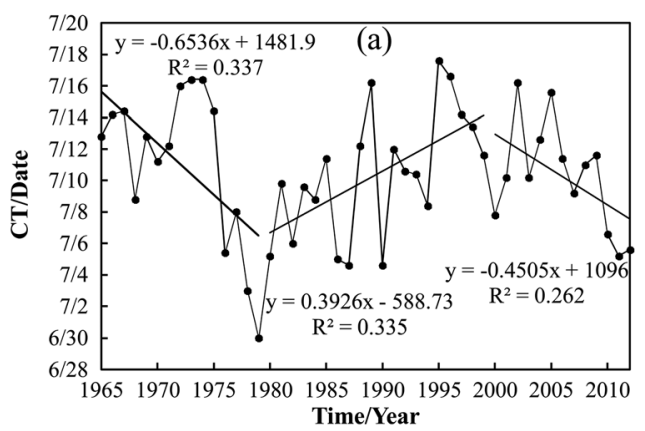

(2009) indicated that the CT was not only impacted by climate change but also influencing the runoff. Through a partial correlation analysis, the CT was correlated positively with runoff in this study (Table IV). Specifically, earlier CTs were associated with reduced runoff, and later CTs were associated with increased runoff, which was consistent with the results for the SMP.

\section{Snow melting process}

Snow melting runoff, which showed spatial variation at different elevations, was impacted directly by temperature. The temperatures in the study area were the highest in July and August, when temperatures were sometimes higher than $0^{\circ} \mathrm{C}$ at elevations above 5350 m.a.s.l. where the SME was larger than those in seasonal snow covered areas. Comparably, the permanent snow covered area had an insignificant SME during the other months because the temperatures were mostly near or below $0^{\circ} \mathrm{C}$ (Figure 9a). In seasonal snow covered areas, because the SCA was the largest and the average air temperature was close to the snow melting temperature at elevations of 4900-5100 m. a.s.l. (Biggs and Whitaker, 2012), the regional SME was dramatically larger here compared with the other areas. The SME at elevations of 5100-5350 m.a.s.l. was only significantly larger than that at elevations of $4700-4900 \mathrm{~m}$ .a.s.l. during July and August, which revealed that with the temperature increase, the source of the melt was

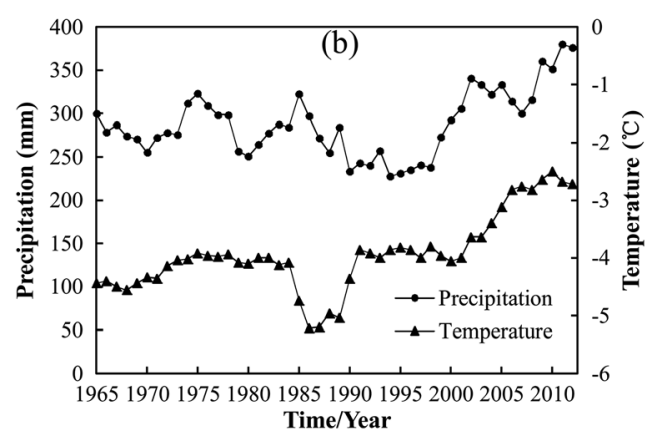

Figure 8. Five-year moving average values of (a) CT for the Tuotuo River hydrometric station and (b) P and $\mathrm{T}$ for the Tuotuo River meteorological station between 1960 and 2012 
Table IV. Pearson R of correlation between CT and climate and hydrological factors for period of 1960-2012

\begin{tabular}{llrl}
\hline & CT $-\mathrm{P}$ & $\mathrm{CT}-\mathrm{T}$ & $\mathrm{CT}-\mathrm{R}$ \\
\hline Pearson correlation & $0.374 * *$ & 0.064 & $0.322^{*}$ \\
Partial correlation & $0.203 *$ & -0.023 & 0.094 \\
\hline
\end{tabular}

$\mathrm{R}$ presents stream flow.

$* *$ is significant at the 0.01 level.

*is significant at the 0.05 level.

gradually transferred to the higher elevation areas where the percentage of snow cover was higher.

During the wet season, there were two peaks in the SME for the Tuotuo River basin; the SME was relatively smooth in July and August, and it stayed in the range of $0.7 \times 10^{6}-1.2 \times 10^{6} \mathrm{~m}^{3} /$ day (Figure $9 \mathrm{~b}$ ). The first peak in the SME occurred in early June, which was shortly after the ST that was initiated by increasing temperatures; however, the second peak in the SME occurred in late September, which was close to the ET that was terminated by increasing snowfall (Woo and Thorne, 2006). Consistent with the results for the ET from the aforementioned analyses, the SME was reduced to zero in early October in the basin from 2000 onward. The Pearson correlation coefficients between the SME and the average temperature and precipitation were 0.80 and 0.51 , respectively, and these were found to be significant at the 99\% confidence level. This indicated that the warmer and wetter conditions resulting from climate change can increase the SME significantly in the study area (Zhang $\mathrm{G}$ et al., 2006).

\section{Snowmelt contribution to the runoff}

Runoff is mainly supplied by rainfall and the melting of ice and snow in the Tuotuo River basin (Xu et al., 2008). As a driving factor of the runoff variation, the impact of rainfall is reflected more directly on the surface runoff (Cao et al., 2011). However, because of hysteresis related to climate change, the melt runoff may influence the baseflow more readily. The Pearson correlation coefficient between the baseflow evaluated by the filter method and the value calculated for the (Q50/Q90) ratio was 0.7 , and it was found to be significant at the $99 \%$ confidence level. Therefore, this magnitude of baseflow can be used in the runoff analysis. The comparison among the snowmelt, baseflow and observed total runoff showed that there were good positive correlations among these variables, and the Pearson correlation coefficients between snowmelt with baseflow and total runoff were 0.66 and 0.68 , respectively; these values were found to be significant at the $99 \%$ confidence level. Under the integrated effects of the SCA and SMP change, the snowmelt presented a fluctuation trend during the period from 2000 to 2010 . The average contributions of snowmelt to the baseflow and total runoff were $19.6 \%$ and $6.8 \%$, respectively, in the Tuotuo River basin (Figure 10a).

The highest snowmelt contributions to runoff were observed from June to October (Figure 10b). Although the snowmelt was relatively smooth, the baseflow and total runoff increased at first and then decreased because of the increase in rainfall. Therefore, the snowmelt contributions to the daily baseflow and total runoff were reduced from $81.9 \%$ and $27.5 \%$ in the start of June to $14.6 \%$ and $5.1 \%$ in late August, respectively. The source of snowmelt was concentrated in the permanent snow covered area and higher elevations in July and August; however, it was derived from the middle and lower elevations in the other periods, which showed that the contribution from seasonal snowmelt to the runoff in the alpine basins cannot be ignored.

\section{DISCUSSION}

\section{Correlation between snow variables and climate change}

In a high-altitude catchment, as an important component of the hydrological processes, snow accumulation and ablation rule the temporal dynamics of water availability. In this environment, the evaluation of the snow water amount is absolutely a crucial issue. Moreover, correct identification of the SCA and SMT variability is the premise of the quantitative analysis of SME.
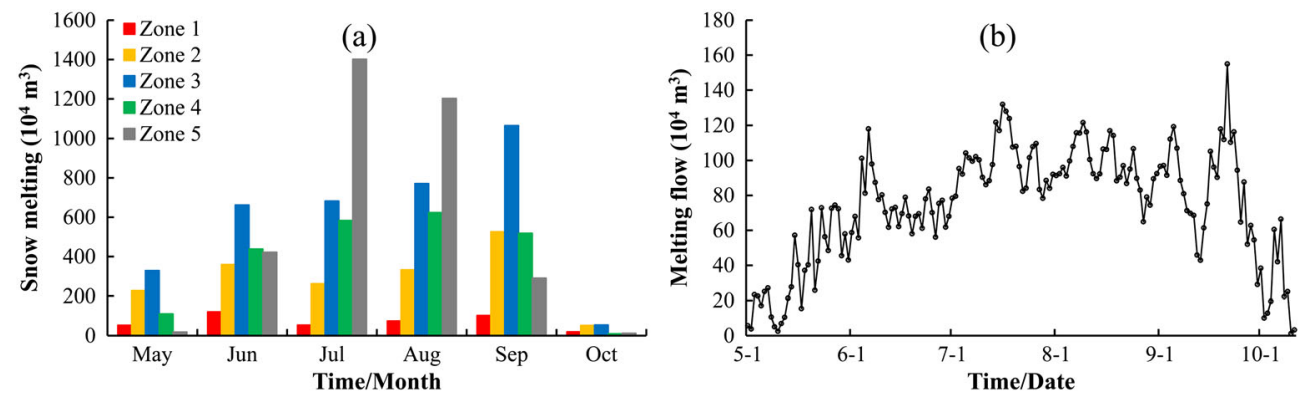

Figure 9. Average annual variance of snow melting equivalent from (a) five elevation zones and (b) the whole basin for 2000-2012 

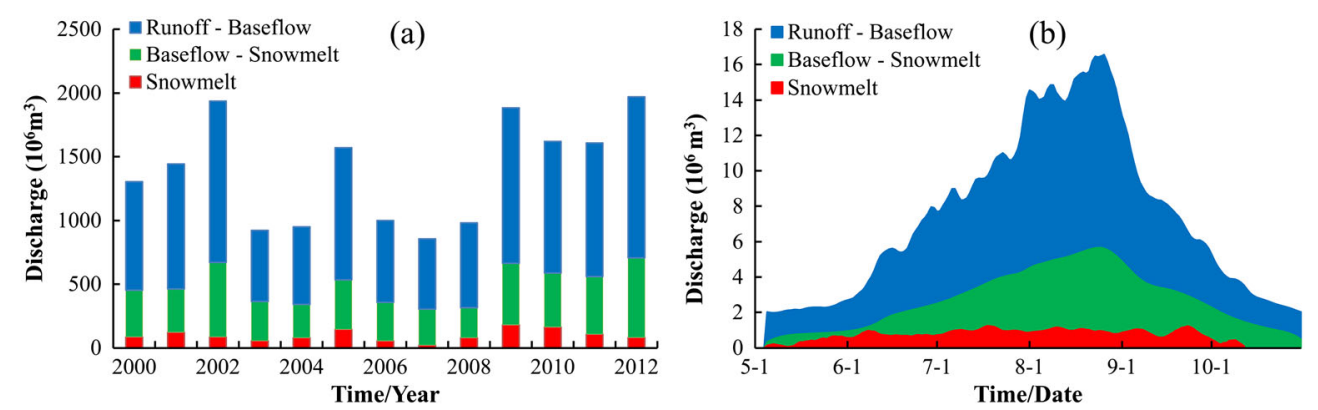

Figure 10. Composition of stream flow in the Tuotuo River basin, showing that (a) inter-annual variation and (b) average annual variation of total runoff, baseflow and snowmelt between 2000 and 2012

On the one hand, the snow cover percentage and the tendency of snow cover variability increased with elevation in the study area, which was consistent with observations in the Himalayan regions made by Khadka et al. (2014). On the other hand, different from the increasing trend of SCA here, Immerzeel et al. (2009) found a negative trend in Himalayan regions. The reason for these opposite trends may be that the climate warming in the Himalayan regions was more intense than in the study area (IPCC, 2007) or that the investigated period was relatively short and regional differences were amplified (Mishra et al., 2014). However, there were more regions where the snow covered time during the wet season was longer than that during the dry season in 2000, but an opposite pattern was observed in 2012 (Figure 6), which indirectly confirmed that the impact of warmer and wetter climate changes on snow cover in the study area has grown (Xu et al., 2009). The precipitation during the dry season and the temperature during the wet season increased, and as a result, the snow cover percentage at higher elevations was more significant than that at lower elevations. In addition, there have been reports about glacial recession in the Tuotuo River basin in recent years (Zhang et al., 2008; Wu et al., 2013), but an increasing trend in the annual SCA was observed in the permanent snow covered area, especially during the dry season. It illustrates that the snow cover variability is more sensitive than that of glacier to the climate change.

Snow cover variation has a direct correlation with the snow melting process, which is driven by the temperature dynamics. Under the warmer and wetter climate scenario, a longer SMP was found in the study area. It is worth noting that it is mainly manifested in advance for the snowmelt starts in the permanent snow covered area and in delay for the snowmelt ends in the seasonal SCA. The spatial-temporal variability of the SMP suggested that the climate warming during the dry season was stronger than that during the wet season, which was also indicated by $\mathrm{Su}$ et al. (2006). Additionally, compared with the higher elevations, climate change in the lower areas was more intense, which was consistent with the characteristics of the source region of Yangtze River in Liang et al. (2013). However, earlier starts to snowmelt during periods when water availability from other sources is scarce pose difficulties for water supply management and ecosystem health (Stewart et al., 2004).

The variability of snow cover and SMT not only reflect the integrated effect of climate change but also influence the runoff regime of the basin. The SME is positively correlated with the SCA and the SMP, which showed that the increase of SCA and the extension of the SMP had positive effects on the increase of the SME. Therefore, the warmer and wetter climate changes will continue to increase the snow water amount in the future. The snowmelt contribution to the runoff will play a more important role in the hydrological processes of highaltitude catchments.

\section{Uncertainty analyses}

In this study, an 8-day combination dataset of MODIS snow cover product was applied to extract the spatial and temporal variations of the snow cover. Because of the lack of snow cover observation data, this is the most reliable dataset available in the alpine catchment currently; however, the time series of this product was relatively short. Construction of a reliable long-term snow cover record is highly recommended.

The typical degree-day model, which has only one key parameter (DDF), was utilized to calculate the snowmelt equivalent in this study. To improve the reliability of the results, the parameter DDF was set to different values for different elevation zones and different periods. However, the validation of the parameter needs to be supported by more observation data in the future.

\section{CONCLUSIONS}

This study discussed the snow cover change, calculated the daily snowmelt equivalent and illuminated the snowmelt contribution to the baseflow and total runoff 
in the Tuotuo River basin, which is the source region of the Yangtze River in China. The analyses were based on the MODIS snow cover product and spatial temperature data. The spatial variation of snow cover was large, and the data showed that the snow cover percentage and the tendency of snow cover variability increased with altitude. From 2000 to 2012, warmer and wetter conditions due to climate change resulted in an increase of the SCA.

Similar characteristics of SMT were obtained with different methods that used data on the temperature and runoff, which indicated that the data were reliable. The analysis of the long-term series (1960-2012) of temperature indicated that the ST of the snow melt in the study area has become earlier by $0.9-3$ days/10a and the ET has become later by $0.6-2.3$ days/10a. In the QinghaiTibetPlateau, this change was relatively slow, which corresponds to weaker climate warming compared with other regions (Yao, 2002).

The average contributions of snowmelt to baseflow and total runoff were $19.6 \%$ and $6.8 \%$, respectively. Under the scenario of climate change, discussions of snow cover variability and snowmelt contributions in alpine basins are important for understanding the runoff composition and ensuring that water resources are adequately managed and protected. We hope that findings from this study will serve as a reference for future research in areas where observational data are deficient and in the planning of future water management strategies for the source region of the Yangtze River.

\section{ACKNOWLEDGEMENTS}

The study is funded by the National Natural Science Foundation of China (grant no. 41201035, 41371058 and 41190080) and the Special Fund of Strategic Leading Science and Technology of Chinese Academy of Sciences (grant no.XDB05030400).

\section{REFERENCES}

Aurela M, Laurila T, Tuovinen JP. 2004. The timing of snow melt controls the annual $\mathrm{CO}_{2}$ balance in a subarctic fen. Geophysical Research Letters 31: L16119.

Barnett TP, Adam JC, Lettenmaier DP. 2005. Potential impacts of a warming climate on water availability in snow dominated regions. Nature 438: 303-309.

Barry RG. 1981. Mountain weather and climate. Methuen: New York.

Bavay M, Lehning M, Jonas T, Löwe H. 2009. Simulations of future snow cover and discharge in Alpine headwater catchments. Hydrological Processes 23: 95-108.

Bavay M, Grünewald T, Lehning M. 2013. Response of snow cover and runoff to climate change in high Alpine catchments of Eastern Switzerland. Advances in Water Resources 55: 4-16.

Biggs TW, Whitaker TM. 2012. Critical elevation zones of snowmelt during peak discharges in a mountain river basin. Journal of Hydrology 438-439: 52-65.
Bookhagen B, Burbank DW. 2010. Toward a complete Himalayan hydrological budget, spatiotemporal distribution of snowmelt and rainfall and their impact on river discharge. Journal of Geophysical Research, Earth Surface 115(F3): F03019.

Cao L, Zhang Y, Shi Y. 2011. Climate change effect on hydrological processes over the Yangtze River basin. Quaternary International 244: 202-210.

Chen T, Liang S, Qian K, Wan L. 2008. Regularity and cause of vegetation coverag changes in the headwaters of the Changjiang River over the last 22 years. Earth Science Frontiers 15: 323-331. (in Chinese with English abstract)

Chen B, Zhang X, Tao J, Wu J, Wang J, Shi P, Zhang Y, Yu C. 2014. The impact of climate change and anthropogenic activities on alpine grassland over the Qinghai-Tibet Plateau. Agricultural and Forest Meteorology 189-190: 11-18.

Eckhardt K. 2005. How to construct recursive digitalfilters for baseflow separation. Hydrological Processes 19: 507-515.

Eckhardt K. 2008. A comparison of baseflow indices, which were calculated with seven different baseflow separation methods. Journal of Hydrology 352: 168-173.

Hall DK, Riggs GA, Salomonson VV, DiGirolamo NE, Bayr KJ. 2002. MODIS snow cover products. Remote Sensing of Environment 83: 181-194.

Hock R. 2003. Temperature index melt modelling in mountain areas. Journal of Hydrology 282: 104-115.

Horton P, Schaefli B, Mezghani A, Hingray B, Musy A. 2006. Assessment of climate change impacts on alpine discharge regimes with climate model uncertainty. Hydrological Processes 20: 2091-2109.

Immerzeel WW, Droogers P, Jong SM de, Bierkens MFP. 2009. Largescale monitoring of snow cover and runoff simulation in Himalayan river basins using remote sensing. Remote Sensing of Environment 113: 40-49.

Immerzeel WW, Ludovicus PH, Bierkens MF. 2010. Climate change will affect the Asian water towers. Science 328: 1382.

IPCC. 2007. Climate change 2007, Impacts, adaptation and vulnerability. Cambridge University Press: Cambridge.

Jain SK, Goswami A, Saraf AK. 2010. Assessment of snowmelt runoff using remote sensing and effect of climate change on runoff. Water Resources Management 24: 1763-1777.

Kane D, Gieck R, Hinzman L. 1997. Snowmelt Modeling at Small Alaskan Arctic Watershed. Journal of Hydrologic Engineering 2: 204-210.

Kang S, Zhang Y, Qin D, Ren J, Zhang Q, Bjorn G, Paul AM. 2007. Recent temperature increase recorded in an ice core in the source region of Yangtze River. Chinese Science Bulletin 52: 825-831.

Khadka D, Babel MS, Shrestha S, Tripathi NK. 2014. Climate change impact on glacier and snow melt and runoff in Tamakoshi basin in the Hindu Kush Himalayan (HKH) region. Journal of Hydrology 511: 49-60.

Kirdyanov A, Hughes M, Vaganov E, Schweingruber F, Silkin P. 2003. The importance of early summer temperature and date of snow melt for tree growth in the Siberian Subarctic. Trees 17: 61-69.

Li L, Maier HR, Partington D, Lambert MF, Simmons CT. 2014. Performance assessment and improvement of recursive digital baseflowfilters for catchments with different physical characteristics and hydrological inputs. Environmental Modelling \& Software 54: 39-52.

Liang C, Zhao L, Zhang B. 2013. Effects of climate change on hydrological environment in the extremely frigid zone of the source region of Yangtze River. South-to-North Water Transfers and Water Science \& Technology 11: 81-86. (in Chinese with English abstract)

Lu A, Jia S, Yan H, Yang G. 2009. Temporal variations and trend analysis of the snowmelt runoff timing across the source regions of the Yangtze River, Yellow River and Lancang River. Resources Science 31: 1704-1709. (in Chinese with English abstract)

Mishra B, Babel MS, Tripathi NK. 2014. Analysis of climatic variability and snow cover in the Kaligandaki River Basin, Himalaya, Nepal. Theoretical and Applied Climatology 116: 681-694.

Mukhopadhyay B, Dutta A. 2010. A stream water availability model of Upper Indus Basin based on a topologic model and global climatic datasets. Water Resources Management 24: 4403-4443.

Nathan RJ, Mcmahon TA. 1990. Evaluation of automated techniques for base flow and recession analyses. Water Resources Research 26: 1465-1473. 
Ohmura A. 2001. Physical basis for the temperature-based melt index method. Journal of Applied Meteorology 40: 753-761.

Painter TH, Rittger K, McKenzie C, Slaughter P, Davisc RE, Dozier J. 2009. Retrieval of subpixel snow covered area, grain size, and albedo from MODIS. Remote Sensing of Environment 113: 868-879.

Parajka J, Blöschl G. 2008. The value of MODIS snow cover data in validating and calibrating conceptual hydrologic models. Journal of Hydrology 358: 240-258.

Parajka J, Pepe M, Rampinic A, Rossid S, Blöschl G. 2010. A regional snow-line method for estimating snow cover from MODIS during cloud cover. Journal of Hydrology 381: 203-212.

Partington D, Brunner P, Simmons CT, Werner AD, Therrien R, Maier HR, Dandy GC. 2012. Evaluation of outputs from automated baseflow separation methods against simulated baseflow from a physically based, surface water-groundwater flow model. Journal of Hydrology 458-459: $28-39$.

Pu Z, Xu L. 2009. MODIS/Terra observed snow cover over the Tibet Plateau, distribution, variation and possible connection with the East Asian Summer Monsoon (EASM). Theoretical and Applied Climatology 97: 265-278.

Qiao C, He X, Ye B. 2010. Study of the degree-day factors for snow and ice on the Dongkemadi Glacier, Tanggula Range. Journal of Glaciology and Geocryology 32(2): 257-264. (in Chinese)

Regonda SK, Rajagopalan B, Clark M, Pitlick J. 2005. Seasonal cycle shifts in hydroclimatology over the western United States. Journal of Climate 18: 372-384.

Sharma V, Mishra VD, Joshi PK. 2012. Snow cover variation and streamflow simulation in a snow-fed river basin of the Northwest Himalaya. Journal of Mountain Science 9: 853-868.

Shi Y, Liu C, Wang Z, Liu S, Ye B. 2005. A concise China glacier inventory. Shanghai Popular Science Press: Shanghai; 111-127. (in Chinese)

Siderius C, Biemans H, Wiltshire A, Rao S, Franssen WHP, Kumar P, Gosain AK, Vliet van MTH, Collins DN. 2013. Snowmelt contributions to discharge of the Ganges. Science of the Total Environment 468-469: S93-S10.

Singh P, Kumar N. 1997. Impact assessment of climate change on the hydrological response of a snow and glacier melt runoff dominated Himalayan river. Journal of Hydrology 193: 316-350.

Singh P, Kumar N, Arora M. 2000. Degree-day factors for snow and ice for Dokriani Glacier, Garhwal Himalayas. Journal of Hydrology 235: 1-11.

Smakhtin VU. 2001. Low flow hydrology, a review. Journal of Hydrology 240: $147-186$.

Stewart IT, Cayan DR, Dettinger MD. 2004. Changes in snowmelt runoff timing in western North America under a "business as usual" climate change scenario. Climatic Change 62: 217-232.

Stone RS, Dutton EG, Harris JM, Longenecker D. 2002. Earlier spring snowmelt in northern Alaska as an indicator of climate change. Journal of Geophysical Research 107(D10): ACL10-1-ACL10-13.

Su B, Jiang T, Jin W. 2006. Recent trends in observed temperature and precipitation extremes in the Yangtze River basin, China. Theoretical and Applied Climatology 83: 139-151.

Tekeli AE, Akyürek Z, Şorman AA, Şensoy A, Şorman A. 2005. Using MODIS snow cover maps in modeling snowmelt runoff process in the eastern part of Turkey. Remote Sensing of Environment 97: 216-230.
Wang G, Cheng G. 2000. Eco-environmental changes and causative analysis in the source regions of the Yangtze and Yellow Rivers, China. The Environmentalist 20: 221-232.

Wang G, Cheng G, Shen Y. 2001. Ecological environment change and its comprehensive protection in Yangtze and Yellow headwater region. Lanzhou: China. (in Chinese)

Westerling AL, Hidalgo HG, Cayan DR, Swetnam TW. 2006. Warming and earlier spring increases western U.S. forest wildfire activity. Science 313: $940-843$.

Wipf S, Stoeckli V, Bebi P. 2009. Winter climate change in alpine tundra, plant responses to changes in snow depth and snowmelt timing. Climatic Change 94: 105-121.

WMO. 1986. Intercomparison of models for snowmelt runoff. Operational Hydrology Report 23(WMO No. 646). World Meteorological Organization: Geneva, Switzerland.

Woo MK, Thorne R. 2006. Snowmelt contribution to discharge from a large mountainous catchment in subarctic Canada. Hydrological Processes 20: 2129-2139.

Wu S, Yao Z, Huang H, Liu Z, Liu G, 2012. Responses of glaciers and glacial lakes to climate variation between 1975 and 2005 in the Rongxer basin of Tibet, China and Nepal. Regional Environmental Change 12: 887-898.

Wu S, Yao Z, Huang H, Liu Z, Chen Y. 2013. Glacier retreat and its effect on stream flow in the source region of the Yangtze River. Journal of Geographical Sciences 23: 849-859.

Xu J, Yang D, Yi Y, Lei Z, Chen J, Yang W. 2008. Spatial and temporal variation of runoff in the Yangtze River basin during the past 40 years. Quaternary International 186: 32-42.

Xu J, Grumbine RE, Shrestha A, Eriksson M, Yang X, Wang Y, Wilkes A. 2009. The melting Himalayas, cascading effects of climate change on water, biodiversity, and livelihoods. Conservation Biology 23: 520-530.

Yang Z, Liu X, Zeng Q. 2000. Chinese cold regions hydrology. Science Press: Beijing. (in Chinese)

Yang C, Zhao Z, Ni J, Ren X, Wang Q. 2012. Temporal and spatial analysis of changes in snow cover in western Sichuan based on MODIS images. Science China Earth Sciences 55: 1329-1335.

Yao T. 2002. Trend features of cryosphere in the center of Tibetan Plateau. Geological Publishing House: Beijing; 169-206. (in Chinese)

Yu MY, Chen X, Li LH, Bao AM, Mupenzi Jean de laPaix, 2013. Incorporating accumulated temperature and algorithm of snow cover calculation into the snowmelt runoff model. Hydrological Processes 27: 3589-3595.

Zhang G, Shi X, Li D, Wang Q, Dai S. 2006. Climate change in Tuotuohe area at the head waters of Yangtze River. Journal of Glaciology and Geocryology 28: 678-685. (in Chinese with English abstract)

Zhang Y, Liu S, Ding Y. 2006. Observed degree-day factors and their spatial variation on glaciers in western China. Annals of Glaciology 43 : 301-306.

Zhang Y, Liu S, Xu J, Shangguan D. 2008. Glacier change and glacier runoff variation in the Tuotuo River basin, the source region of Yangtze River in western China. Environmental Geology 56: 59-68.

Zhou X, Xie H, Hendrickx J. 2005. Statistical evaluation of MODIS snow cover products with constraints from streamflow and SNOTEL measurement. Remote Sensing of Environment 94: 214-231. 